\title{
24-h variations of blood serum metabolites in high yielding dairy cows and calves
}

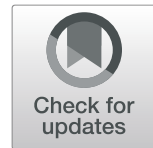

Hussein Awad Hussein ${ }^{1^{*}} \mathbb{D}$, Jan-Peter Thurmann ${ }^{2}$ and Rudolf Staufenbiel ${ }^{2}$

\begin{abstract}
Background: Blood profile testing is commonly used to monitor herd health status, diagnose disorders, and predict the risk of diseases in cows and calves, with subsequent optimization the production of dairy herds. By understanding the physiological ranges of serum metabolites relative to age, lactation stage, and the sampling time in healthy cows and calves, the dairy practitioners can accurately diagnose abnormalities with a blood test. The effect of sampling time on the variation of serum metabolites within $24 \mathrm{~h}$ were evaluated in 83 cattle. All animals were originated from a dairy herd, where the animals, based on their ages and lactation stages, were classified into eight groups. The blood samples were collected from each animal every $4 \mathrm{~h}$ within a day.

Results: The time of sampling within the day showed significant influences on the serum concentrations of glucose, $\beta$-hydroxybutyric acid (BHBA) and urea. BHBA was the most metabolite that showed day variation among cows' groups. Furthermore, the concentrations of total cholesterol were the most stable metabolite in all groups. The mean values of albumin, total proteins, glucose, non-esterified fatty acids (NEFA), BHBA, total cholesterol, total bilirubin, urea, and creatinine revealed significant variations among the different studied groups.

Conclusions: A certain suitable time of blood sample collection cannot be recommended. However, care shall be taken for the time of sampling for measurements of glucose, NEFA, BHBA and urea, otherwise the comparative values of these metabolites at different sampling time points may differ significantly from each other's, without a disease cause. It may be recommended, for metabolic assessment of dairy herds, classification the subjects into different groups based on lactation stages and ages of animals.
\end{abstract}

Keywords: Calves, Diurnal, Dairy cows, Metabolic profile, Sampling, Variations

\section{Background}

Future health and performance management systems should focus on early identification and subsequent prevention of physiological imbalances in dairy herds. Consequently, there is a need for metabolic indicators that reflecting the health status of cows and calves. Measurement of specific serum metabolites allows the evaluation of adequacy of the main metabolic pathways associated with energy, protein, and minerals and then provides useful information related to nutrition and animal health

\footnotetext{
*Correspondence: hhussein@aun.edu.eg

${ }^{1}$ Internal Veterinary Medicine, Department of Animal Medicine, Faculty of Veterinary Medicine, Assiut University, Assiut 71526, Egypt

Full list of author information is available at the end of the article
}

to optimize the productive and reproductive potential of dairy herds [1]. Recently, using of blood metabolic profiling has acquired relevance for the study and diagnosis of various metabolic and reproductive disorders [2]. Blood parameters including glucose, non-esterified fatty acids (NEFA), $\beta$-hydroxybutyric acid (BHBA), cholesterol, and enzymes and proteins had been reviewed recently to be of great interest for metabolic profiling of dairy herds [3].

Serum metabolites reflecting protein, fat, and carbohydrate metabolism may show a day fluctuation with subsequent difficult interpretations of individual values. Diurnal changes of various blood metabolites have been reported for dairy cows. However, these studies were 
carried out on few numbers of adult cows [4] or conducted to estimate the effect of feed triglycerides and free fatty acids [5] or administration of monensin [6] on the day variations of blood metabolites and hormones.

Healthy calves form the basis of any successful dairy production system, from both an economic and an animal welfare point of view. However, more research is needed before we can rely exclusively on monitoring data for detection of disease in dairy calves; consequently, routine observation of calves to evaluate metabolic health status remains essential [7]. In addition, characterizing serum metabolites in dairy calves could provide further insight into daily metabolic changes and the mechanisms that lead to metabolic diseases [8]. To the best of authors' knowledge, the metabolic assessment and the 24-h variations of serum metabolites in newborn and suckling calves, were not yet been investigated.

From the clinical point of view, the strong factors including the age and lactation stage within-day variations of serum metabolites may be a source of misdiagnosis or improper interpretation of the obtained data, therefore, the objectives of this study were as follows: (1) evaluate whether the diagnostic significance of blood metabolites in high yielding cows and calves depends on the time of sampling within $24 \mathrm{~h}$; (2) assess the group variations of different serum metabolites.

\section{Results}

The day variations of serum albumin are shown in Fig. 1a. The sampling time has no significant effect on the concentrations of albumin $(p>0.05)$, as well as positive and significant AR1 rho was observed $(0.78 ; p<$ 0.001 ), suggesting strong relationship among the measurements taken further apart in time. In contrast, the serum levels of albumin were significantly different among the groups $(p<0.001)$; as the highest values were noticed in fresh-lactation cows and the lowest values were observed in newborn calves (Fig. 1b). The day fluctuations of serum total proteins are illustrated in Fig. 2a. The time points showed no significant effect on the values of total proteins $(p>0.05)$, while its level showed significant variations among the different groups $(p<0.001)$, where the group of dry cows exhibited the highest value and suckling calves showed the lowest one (Fig. 2b).

The time relative to sampling has a significant effect on mean glucose levels $(p<0.001)$, as the values varied within the day (Fig. 3a) and regardless the animal groups, the lowest overall mean of glucose was noticed at 02:00 o'clock. There were significant differences in glucose concentrations among groups $(p<0.001)$. However, presence of time/group interaction, indicating that glucose behaved differently with the preceding of sampling time among the groups. The group variations of serum glucose are illustrated in Fig. 3b. The lowest value of glucose was observed in early-lactation cows, while the highest level was noticed in newborn calves $(p<0.05)$.

Figure 4a illustrates the effect of sampling time during the day, no significant influence on the serum concentrations of NEFA was determined, however, a significant time/group interaction was observed, indicating that NEFA behaved differently within the day among groups. The mean values of NEFA showed significant variations among the different groups $(p<0.001)$, as the highest values were measured in fresh- and early-lactation cows and the lowest were determined in late-lactation ones (Fig. 4b).

The sampling time of the respective day had a significant effect on the concentrations of BHBA $(p<0.001$; Fig. $5 \mathrm{a})$, as the highest overall mean was observed at 18 : 00 o'clock. The relationship among measurements taken further apart in time was $0.54(p<0.001)$. However, there were significant changes in BHBA levels among different groups $(p<0.001)$. Furthermore, a significant time/group interaction was noticed $(p<0.001)$. Cows of
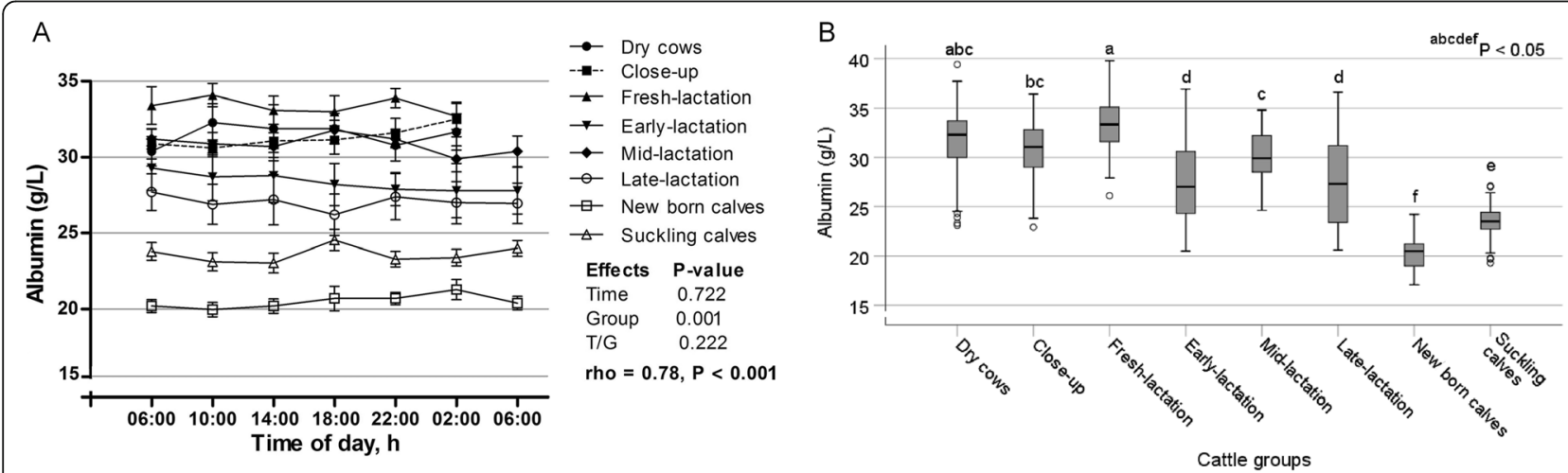

Fig. 1 a Diurnal variations of serum albumin in dairy cows and calves within $24 \mathrm{~h}$ (means \pm SE). $\mathbf{b}$ Box plots show the comparison of serum albumin among the different cattle groups. The plots show median (line within box), 25th and 75th percentiles (box), and minimum and maximum values (whiskers). Plots with different letters differ significantly $(P<0.05)$ 

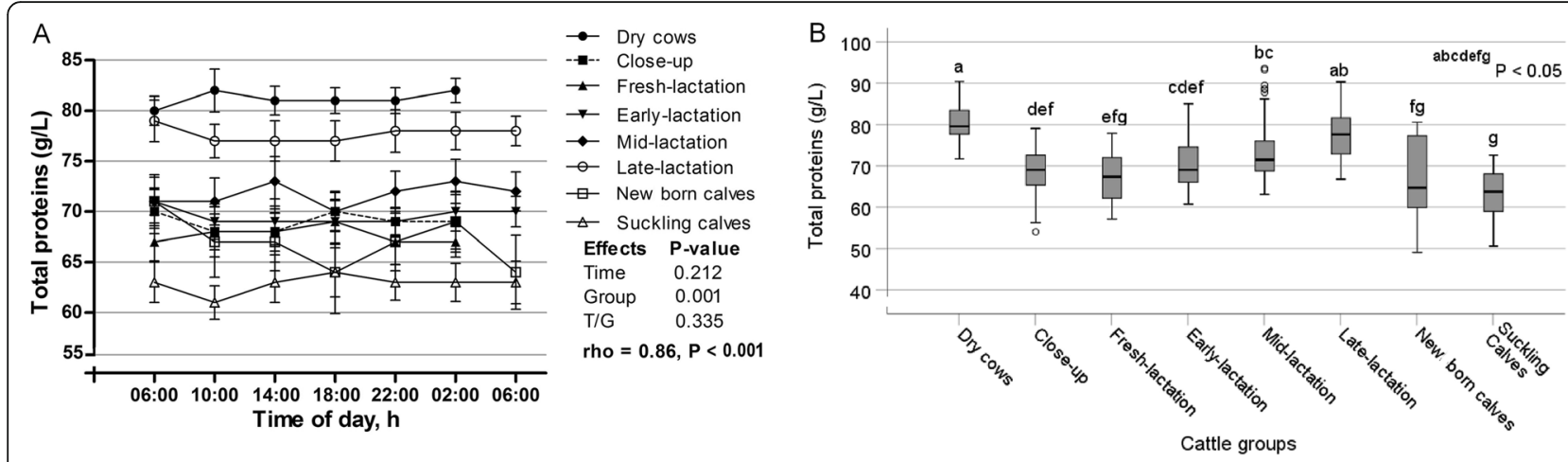

Fig. 2 a Diurnal variations of serum total proteins in dairy cows and calves within $24 \mathrm{~h}$ (means \pm SE). $\mathbf{b}$ Box plots show the comparison of serum total proteins among the different cattle groups

early- and mid-lactation groups showed the highest value of BHBA, while both calves' groups exhibited the lowest concentrations $(p<0.05$; Fig. $5 \mathrm{~b})$.

The diurnal fluctuations of serum total cholesterol are shown in Fig. 6a, where no significant effect for the sampling time was noticed $(p>0.05)$. The serum level of cholesterol was highest in mid-lactation cows and lowest in newborn calves $(p<0.05$; Fig. $6 \mathrm{~b})$, with no significant time/group interaction. Furthermore, a positive and strong correlation coefficient was detected (rho $=0.95$; $p<0.001$ ).

Although the sampling time during the day had no significant influence on the concentrations of total bilirubin $(p=0.088)$, there were significant effects for group and time/group interactions $(p<0.001$; Fig. 7a). The highest and lowest values for total bilirubin were seen in newborn calves and dry cows, respectively $(p<0.05$; Fig. 7b). However, because there was a significant time/group interaction for total bilirubin, this metabolite behaved differently among groups within the day.

The time relative to sampling had a significant effect on the mean values of urea $(p=0.000)$, as the values varied within the day (Fig. 8a) and the highest urea concentration was noticed at 14:00 o'clock. There were significant differences in urea concentrations among groups $(p=0.000)$. However, presence of time/group interaction, indicating that urea behaved differently with the preceding of sampling time among the groups. The group changes of serum urea are shown in Fig. 8b. The highest concentration of urea was observed in latelactation cows, while the lowest value was measured in close-up cows $(p<0.05)$.

The time of sampling during the day had no significant changes on the serum concentrations of creatinine $(p=0.424$; Fig. 9a). In contrast, the group showed significant effect on the creatinine level $(p=0.000)$ with positive AR1 rho value $(0.83 ; p=000)$. Cows of close-up phase revealed the highest value, while newborn calves showed the lowest one $(p<0.05$; Fig. 9b).

\section{Discussion}

In herd management, assessment of the metabolic status have frequently been used to evaluate the nutritional status of dairy cows during the transition period, as well as to monitor the herd health, find subclinical diseases and investigate herd problems with metabolic disorders $[9,10]$.
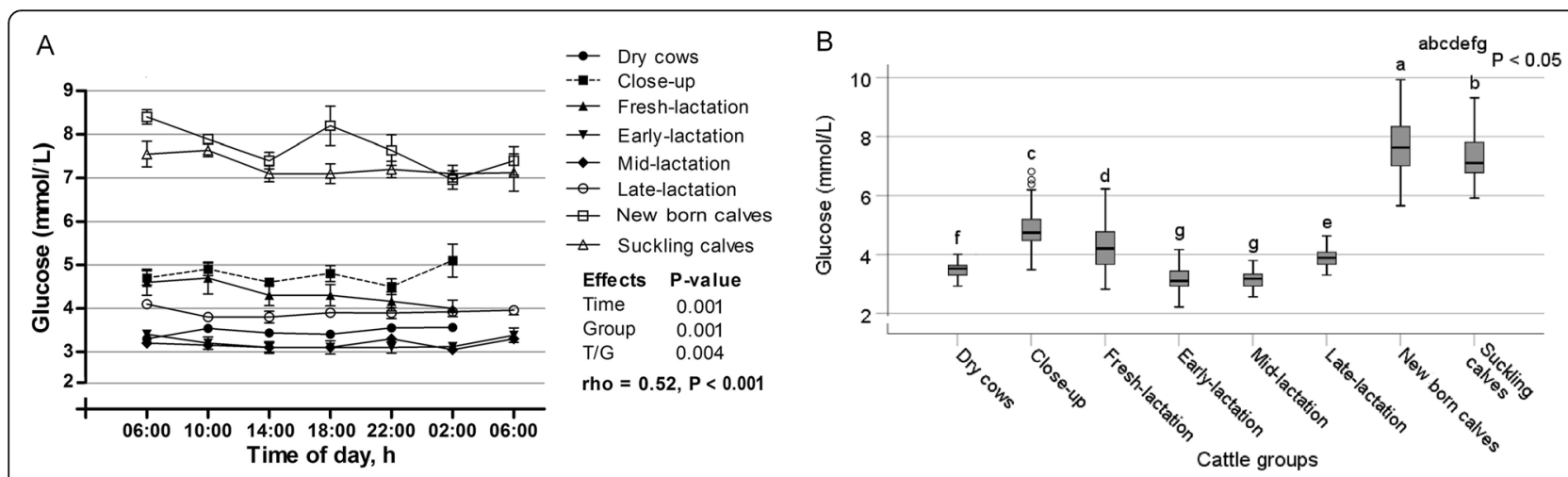

Fig. 3 a Diurnal variations of serum glucose in dairy cows and calves within $24 \mathrm{~h}$ (means \pm SE). $\mathbf{b}$ Box plots show the comparison of serum glucose among the different cattle groups 

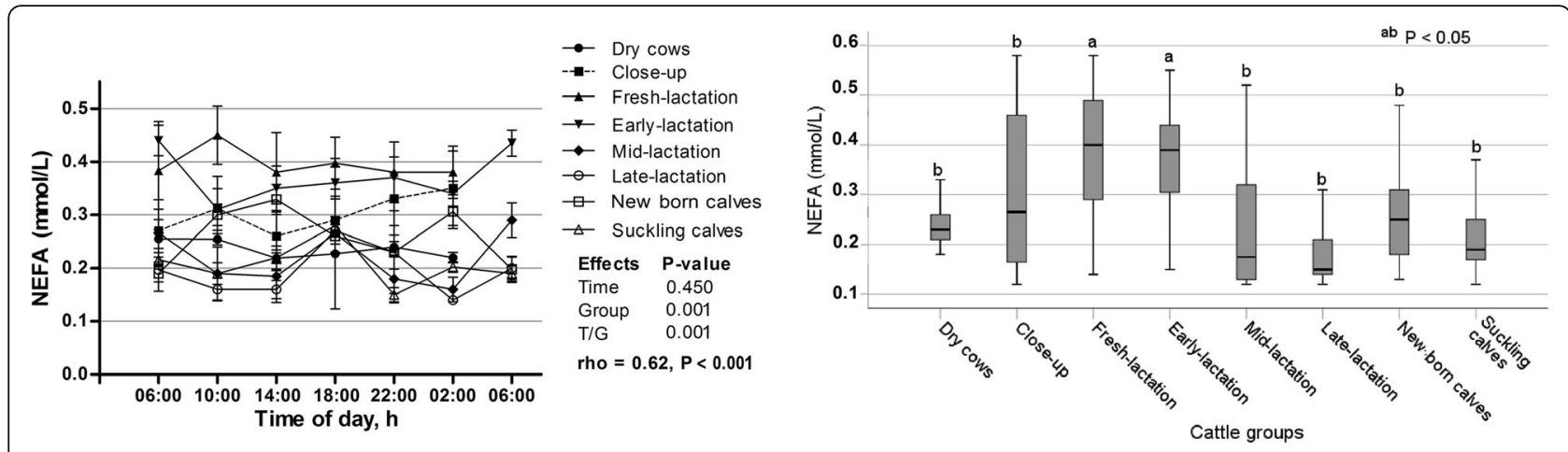

Fig. 4 a Diurnal variations of serum NEFA in dairy cows and calves within $24 \mathrm{~h}$ (means \pm SE). $\mathbf{b}$ Box plots show the comparison of serum NEFA among the different cattle groups

In the present study, the influence of strong factors including age (calves, cows), lactation stage (dry period, close-up, fresh lactation, early lactation, mid-lactation, and late lactation) and the time of day (24-h profile) on blood metabolites were investigated.

The sampling time within the day has no significant effect on the serum albumin concentrations, indicating no day dynamic for serum albumin. The albumin concentrations, in the present study, were within the physiological limits and ranged from 30 to $40 \mathrm{~g} / \mathrm{L}$ [11], with a significant influence for the animal groups on this parameter. Such decrease of albumin concentration in early- and late lactation cows could be explained by the variations of lactation stages. In a previous study [12]; the author attributed the drop of serum albumin after calving to decreased synthesis by the liver and loss from, or dilution in, the blood. The drop of albumin levels in newborn and suckling calves may due to the age factor, as reported elsewhere [13]; calves initially showed decreased albumin concentration 2 days after birth then increased thereafter. Thomas [14] attributed that to increased colostrum uptake with subsequent increased serum globulins. Furthermore, the medium half-life of albumin in ruminant ranges from 14 to 16 days, after that the liver is responsible for albumin synthesis [15].

Within $24 \mathrm{~h}$, the serum concentrations of total proteins were relatively stable without great changes over the time. Supporting this view is that serum proteins may remain reasonably constant over several weeks in an individual, with a coefficient of variation ranged from 3 to $4 \%$ [16]. The concentrations of total proteins, in this research, were within the reference values $(60-80 \mathrm{~g} / \mathrm{L})$ [12]. Conversely, the group showed significant effect on the serum values of total protein, indicating individual variations among the different groups, as it was higher in dry- and late lactation cows, and lower in newborn and suckling calves. The increased serum proteins in dry cows may be explained by the change of metabolic situation after lactation and/or no protein uptake by the mammary gland. It was mentioned before [17], the variation of total protein concentrations during lactation follows a trend comparable with that reported for the variation of milk yield. In addition, Piccione et al. [18] reported that stage of gestation and lactation affected serum total protein concentrations in Holstein-Friesian cows, particularly during the transition from late gestation to
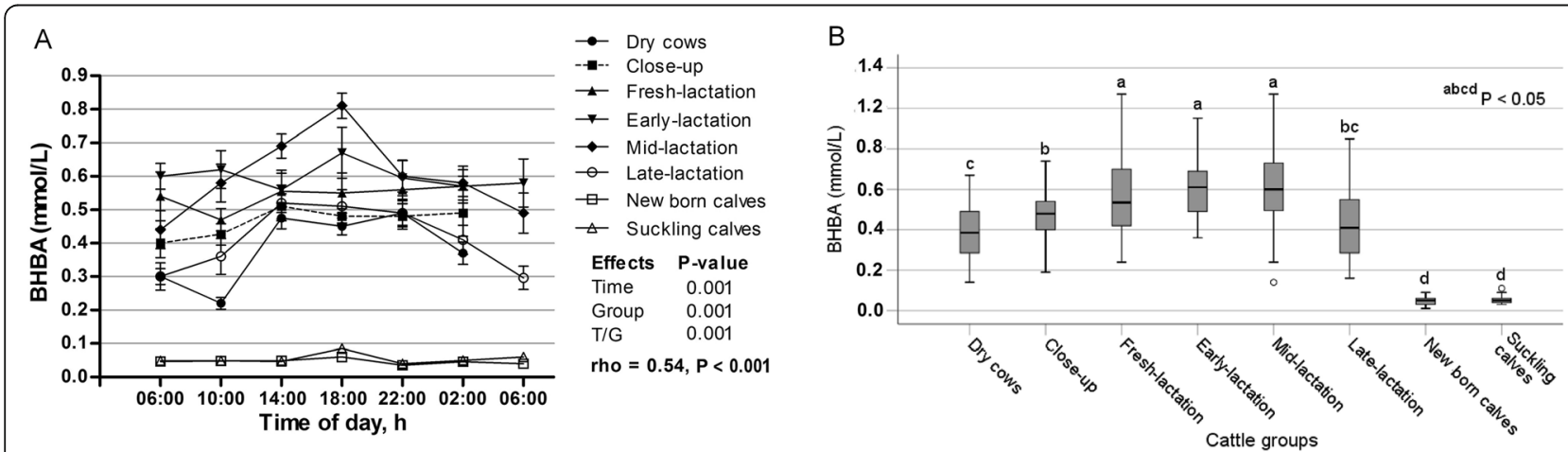

Fig. 5 a Diurnal variations of serum BHBA in dairy cows and calves within $24 \mathrm{~h}$ (means \pm SE). $\mathbf{b}$ Box plots show the comparison of serum BHBA among the different cattle groups 

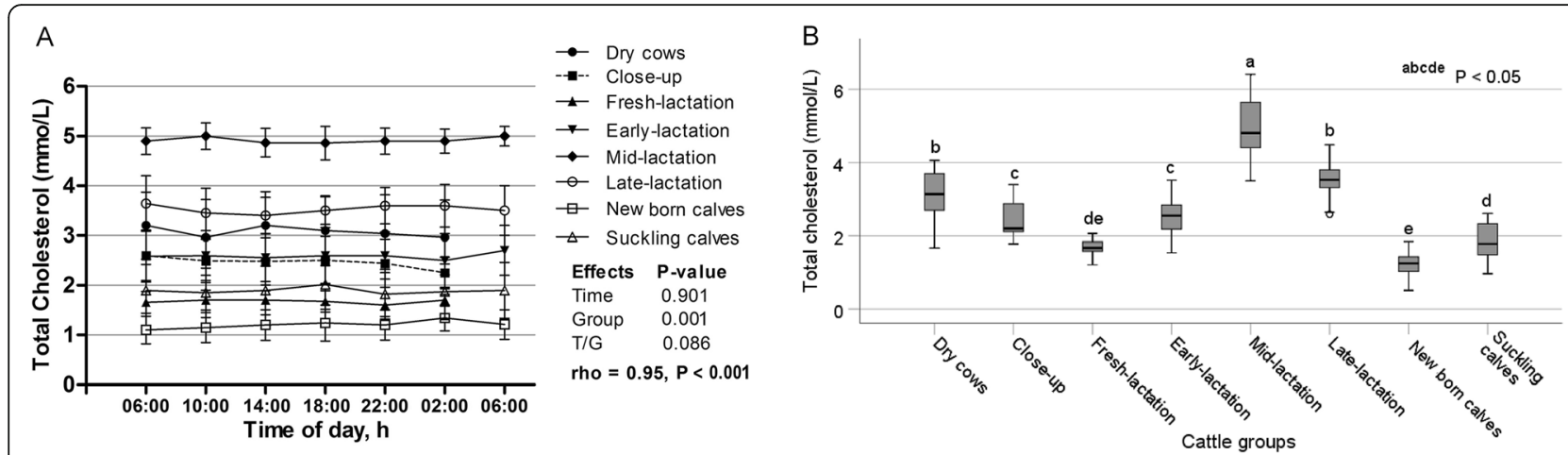

Fig. 6 a Diurnal variations of serum total cholesterol in dairy cows and calves within $24 \mathrm{~h}$ (means \pm SE). $\mathbf{b}$ Box plots show the comparison of serum total cholesterol among the different cattle groups

early lactation, when cows undergo a pronounced metabolic stress. In contrast, Cozzi et al. [19] did not find any effect of lactation stage on serum total proteins. The lower serum protein concentrations in newborn and suckling calves, in this study, may be explained by low protein contents of drinking milk and/or increased anabolism and consumption of proteins for building up of body musculature. After parturition, the newborn and young calves go through a period of rapid growth, development and major physiological adaptations [20].

The sampling time had a significant effect on the glucose concentration, indicating presence of a day dynamic for this parameter. The drop of serum glucose overnight compared with during the day may be attributed to the utilization and consumption of this metabolite by the different body tissues at that time when the intensity of feed intake is low. This presumptive view was supported elsewhere [6, 21], the authors reported that the feeding activity, the extent of rumen fermentation with high rumen volatile fatty acids, and the availability of substrates for gluconeogenesis were higher during the day than at night. Herbein et al. [22] found reduced night glucose concentrations in dairy cows, whereas another study revealed no diurnal variations for glucose [23]. In contrast, Blum et al. [5] reported increased glucose concentrations during the night. The variations between the different studies are likely to be explained by differences in energy intakes, diet compositions, and time of feedings. In a previous study [24], the authors concluded that the feeding time and feed contents affected the concentration of blood glucose in dairy cows. In newborn and suckling calves, the serum glucose concentrations were higher at the first $06.00 \mathrm{~h}$ measurement than at 14.00 and 02:00 h measurements, indicating the diurnal variation of this metabolite, as well as this may be due to the postprandial effect. As the forestomachs of calves, in this study, are not yet developed, therefore the pattern of glucose may seem like that in monogasrtric animals. In monogastrics, it has been reported that minor delays in gastric emptying rate have a notable effect on the glycemic response after a meal [21]. In adult cattle of the current study, only slight glucose fluctuations were found, and the values fluctuated by $3-4 \mathrm{mmol} / \mathrm{L}$ with a standard deviation of $0.23-1.1 \mathrm{mmol} / \mathrm{L}$, which may be attributed to the role of insulin in glucose metabolism [25]. It had reported that insulin play an important role

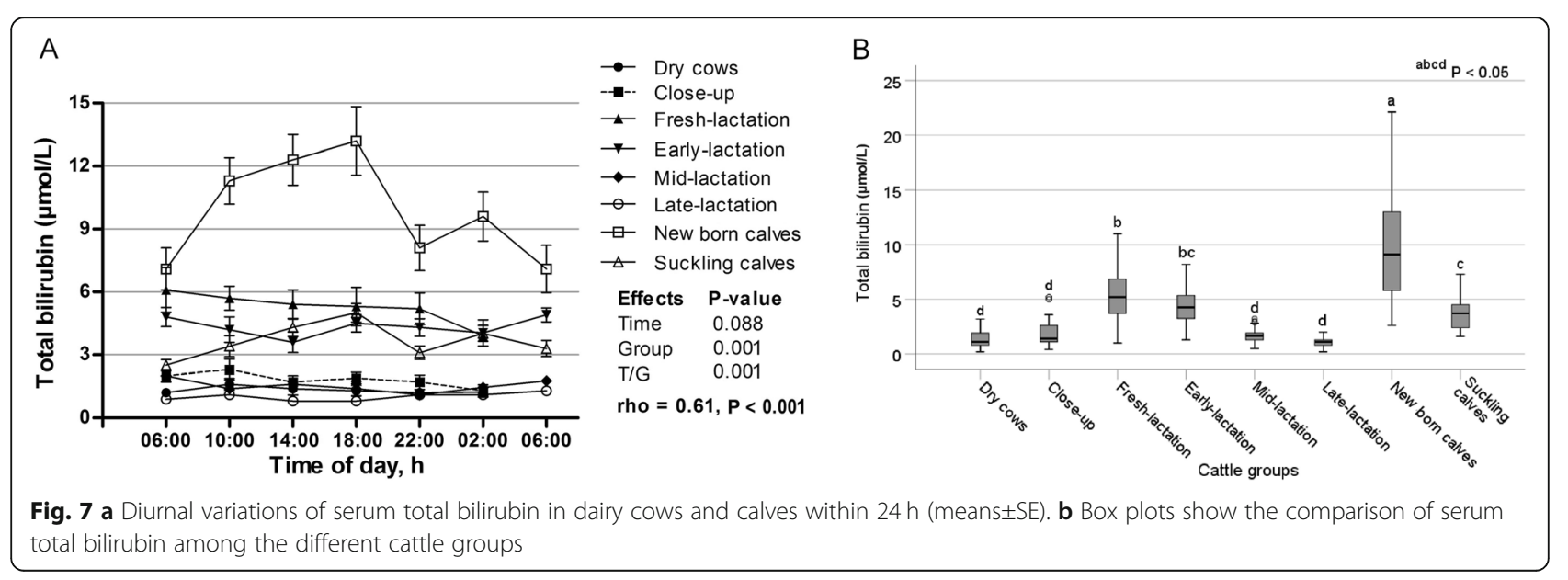



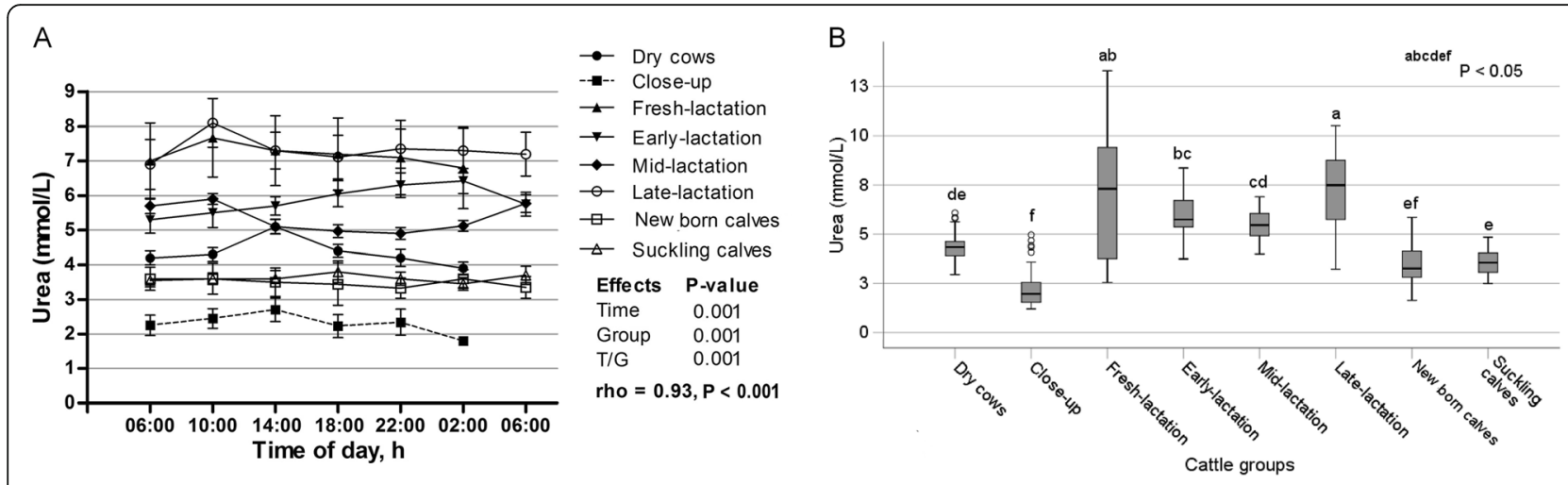

Fig. 8 a Diurnal variations of serum urea in dairy cows and calves within $24 \mathrm{~h}$ (means \pm SE). $\mathbf{b}$ Box plots show the comparison of serum urea among the different cattle groups

in carbohydrate and fat metabolisms leading to lowering of the blood glucose level [12]. In the current study, the serum concentration of glucose showed significant variation among the different groups, as it was higher in newborn and suckling calves, and lower in early- and mid-lactation cows. Such variation may be explained by the change of the metabolic status of each group. Increased glucose level in young calves attributed elsewhere to the composition of milk replacers [26], whereas decreased glucose concentrations in early lactating cows may be as a result of high milk production with subsequent negative energy balance [24].

In the present research, the serum values of NEFA were lower than the critical threshold of $0.57 \mathrm{mmol} / \mathrm{L}$ [27]. In addition, the concentrations of NEFA showed insignificant changes during the $24 \mathrm{~h}$ measurements, indicating stability of this metabolite with the time of day. However, a significant time/group interaction was noticed, indicating that NEFA might show a day variation in some groups. Blum et al. [5] observed a night rise of NEFA concentration in dairy cows. This difference may be due to the variation of diet contents and time of feed delivery [23]. As reported in a previous study [28], infrequent feed delivery will result in a large variation of feeding behavior throughout the day, resulting in a great change in insulin [29] and, subsequently, fat mobilization with resultant increase of serum NEFA [5]. It was observed a significant effect of groups, in the current work, on the serum concentration of NEFA, as it was higher in fresh- and early lactation cows and lower in late lactation cows. Such significant difference could be explained by the negative energy balance after calving. In early lactating cows, NEFA concentration reflects the fat mobilization for compensation the imbalance between nutrients consumed by the cow and nutrients secreted in milk [30].

The serum concentrations of BHBA showed significant change within the day, indicating variability of this metabolite with the time. Variation within $24 \mathrm{~h}$ of serum BHBA was also studied in dairy cows by Blum et al. [5]. In previous studies [23, 29], it was reported that increased serum BHBA after meals was explained by increased conversion of butyrate into BHBA in the ruminal epithelium. All dairy cows, in the current research, were fed either one or two times, but both times
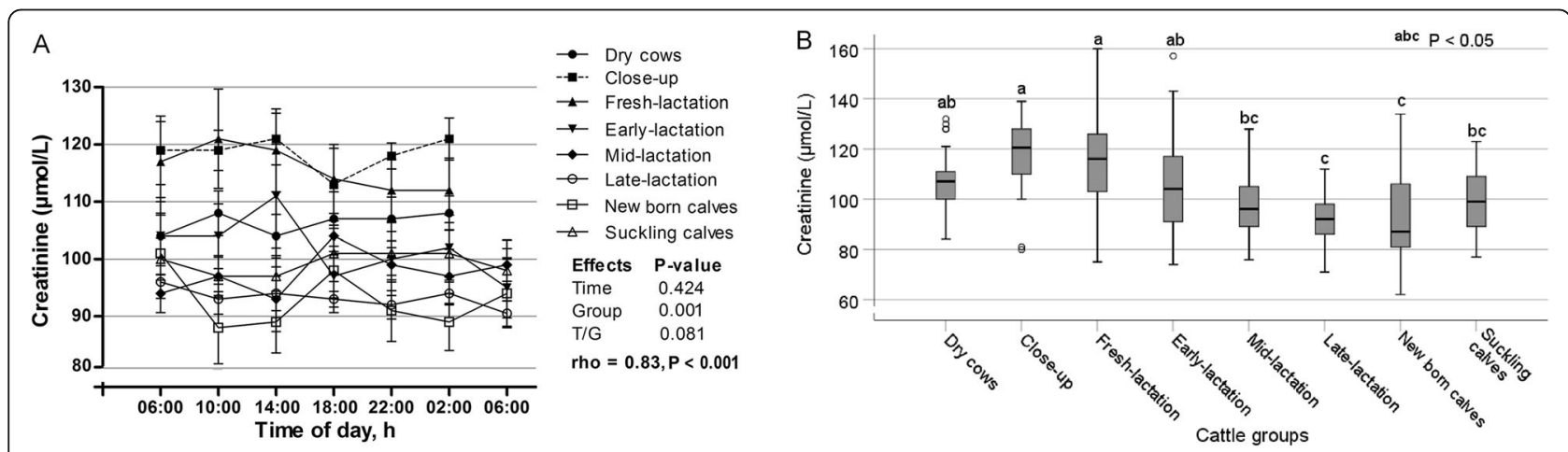

Fig. 9 a Diurnal variations of serum creatinine in dairy cows and calves within $24 \mathrm{~h}$ (means \pm SE). $\mathbf{b}$ Box plots show the comparison of serum creatinine among the different cattle groups 
were within the day as recommended elsewhere [31], which explains increased BHBA during the day after meals in comparison with the night. The highest BHBA concentrations, in this work, could therefore be observed three to ten hours after feeding. It had been reported increased BHBA concentrations after feedings [6, 23]. The animal groups showed a significant influence on the concentration of BHBA, as it was highest in fresh-, earlyand mid-lactation cows. Such increases in these groups could be attributed to the negative energy balance. It is well known that dairy cows at early lactations experience negative energy balance [32]. The lowest values of BHBA were observed among the calves' groups, which might be explained to the underdeveloped rumen physiology, as well as they were fed energy-containing whole milk drinkers. In dairy calves, the rumen starts in development after 4 weeks of age [33].

In the present study, the cholesterol values showed the most stable course of the day among all examined laboratory parameters. This result was coincided with the observations by Wiedemann et al. [4], who failed to demonstrate 24-h variations for serum cholesterol in bovine animals. In contrast, in a previous study in human [34], the author determined a circadian rhythm with an amplitude of $2.5 \%$ in cholesterol daily mean. The cholesterol concentrations showed significant variations among the different groups, as the higher value was noticed in mid-lactation cows. All cows of this group were at the peak of milk production (> $28 \mathrm{~kg} /$ day), which might lead to excessive mobilization of lipid to the liver, as sequel of negative energy balance, with subsequent liver sequestration of cholesterol to the blood stream [35]. The lower mean value of cholesterol, in this research, was measured in newborn calves, which may be due to these calves are only drinking whole milk.

In this work, the mean value of total bilirubin in newborn calves was $9.6 \mu \mathrm{mol} / \mathrm{L}$, above the former mentioned reference value [12]. However, it was stated that serum bilirubin in newborn calves was as high as $9.58 \mu \mathrm{mol} / \mathrm{L}$ [36]. Furthermore, the influence of the time of day could not be statistically verified in the present investigation. However, a significant time/group interaction was detected, indicating that total bilirubin might show a day variation in some groups. Furthermore, the concentrations of total bilirubin in newborn and suckling calves showed the day dynamics. The higher value of this metabolite in the newborn calves may be due to destruction of foetal haemoglobin and slower excretion of bilirubin because of lower concentration of transport protein ligandin, which responsible for passing of indirect bilirubin into hepatocytes where it is transformed to direct bilirubin that can be excreted [12]. In a previous research in calves [37], the authors reported decreased bilirubin concentrations from 1st to the 14th day of age and later it remained stable.
Serum concentrations of urea showed significant variation within $24 \mathrm{~h}$, indicating the day dynamic of this variable, where the highest value was observed at 14:00 o'clock. As all cow groups were supplied with TMR before 14:00 o'clock, which explain the role of feeding behavior on such increase of serum urea. However, calves' groups showed no day variation of serum urea. In a previous research work [38], the authors contributed the role of meal for the day fluctuation of serum urea concentrations. In contrast to the present work, urea concentrations did not depend on sampling time of the day in dairy cows between week 2 antepartum and week 12 postpartum [4]. Such difference may be attributed to the few number of cows at narrow scale of lactation stages in that study. It was observed a significant effect of groups, in this study, on the serum levels of urea, as the mean value was higher in late lactation cows and lower at close-up ones. Such difference may be explained by the variation of TMR. The reason for the increased urea values in late-lactation cows could be due to the higher protein content of the TMR with a low milk yield $(<28$ $\mathrm{kg} /$ day). The changes in urea values are affected by protein metabolism and on the other hand by renal excretion of this metabolite [39].

In the present study, serum concentrations of creatinine in all examined groups lie within the specified reference ranges $88-177 \mu \mathrm{mol} / \mathrm{L}$ [11]. No influence for the time of day, in the current investigation, can be proven on serum creatinine concentrations. In contrast, a significant effect for sampling time within the day was observed in sheep [40]. In this study, the serum creatinine concentrations were significantly affected by the animal groups. The higher values were observed in close-up and fresh-lactation cows, indicating the role of calving and its associated physiological adaptation in such increase. The lower values were measured in newborn calves. The reason may be explained by the lower muscle mass than adult cattle. As a product of muscle metabolism, a recent study reported a direct effect for the muscle mass on the urinary excretion of creatinine [41].

\section{Conclusions}

The present study throws a light on the day variations of blood metabolites, which may be helpful for evaluation the health status in high yielding herds. Based on the results, a certain time of blood sample collection cannot be recommended. Therefore, the time of the sample collection can be adjusted according to the operational processes. However, care shall be taken for the time of sampling of glucose, NEFA, BHBA and urea, otherwise the comparative values of the sampling time points may differ significantly from each other, without a disease cause. It may be advisable, for metabolic profiling of high yielding dairy herds, classification of animals into 
different groups. This classification should be based on the age (young - adult), and lactation stage, to avoid the variation among subjects.

\section{Methods}

The blood sampling procedures reported herein were conducted according to Directive 2010/63/EU, and the regulations of the Institutional Animal Care and Use Committee, Free University of Berlin. All animals were housed, handled and cared according to the rules of German Animal Welfare act (S. 1206, 13,137,833-3/ 18.05.2006) [42].

\section{Animals and management}

The study was performed on a commercial HolsteinFriesian dairy herd in the city of Leipzig, Germany. During the study period, the herd included 1700 dairy cows. The cows had a $305-\mathrm{d}$ milk yield of $11,500 \mathrm{~kg}$ on average (Additional file 1); average milk protein concentration was $3.33 \%$ and milk fat was $3.83 \%$. The lactating cows were milked three times per day with $8 \mathrm{~h}$ apart. Dairy cows were kept in a free-stall barn equipped with individual electronic feeding systems (Landtechnik Weihenstephan, Germany). Water was available ad libitum from a nose-press water bowl. The dairy calves were raised in individual boxes (igloos) only for about 2 (from 1 to 3 ) weeks with straw or wood shavings as beddings; they were then housed in-group boxes until the end of the drinking period. A total number of 83 animals were included in the current study. According to the lactation phases and age of animals, they were classified into eight groups as dry cows $(n=10)$, close-up $(n=10)$, freshlactation $(n=11)$, early-lactation $(n=10)$, mid-lactation $(\mathrm{n}=11)$, late-lactation $(\mathrm{n}=11)$, newborn calves $(\mathrm{n}=10)$ and suckling calves $(\mathrm{n}=10)$. Table 1 summarizes the parity, body condition scores (BCS), investigation stages, and feeding time of studied groups.
All animals were clinically examined before and during the study conduction, and all physical parameters including respiratory and heart rates, and rectal temperatures were within the reference ranges. Furthermore, no animals administered any medicaments, just before or during the study conduction, which may interfere with studied metabolites. Cows of all groups were fed diets of grass and maize silage and concentrate as totally mixed rations (TMR) one time per day after the morning milking. However, cows of mid-lactation group received a second feeding after the second milking. The calves were fed whole milk two times per day at 03:00 and 15:00 o'clock; in addition, the newborn calves were given highquality colostrum containing $50 \mathrm{~g}$ immunoglobulins per litre. The stable temperature and air humidity followed the meteorological changes due to the conditions in the stable structure. However, the animals were housed in the stable all over the year with adequate aeration.

\section{Blood sampling and study design}

In adult dairy cows, blood samples were collected from the tail veins after fixation of cows using 18-gauge cannulas (Sterican, $1,20 \times 40 \mathrm{~mm}$, B. Braun Melsungen AG, Melsungen, Germany). In calves, the blood samples were obtained by puncture of jugular vein using catheters (14 G, $2.1 \times 50 \mathrm{~mm}$, Braun, Germany), which were fixed in the skin after shaving and disinfection. All blood samples were collected in $9 \mathrm{ml}$ vacutainer tubes without anticoagulant (Monovet $9 \mathrm{ml}$ Z, SARSTEDT AG \& Co., Nümbrecht, Germany). Blood samples were taken at $4 \mathrm{~h}$ interval over $24 \mathrm{~h}$ period, starting at 06:00 o'clock, and ending at 06:00 o'clock of the following day, indicating 7 blood samples were collected from each animal. Except in dry, close-up and fresh-lactation cows, blood collection started at 06:00 o'clock and ended at 02:00 o'clock of the following day, indicating 6 blood samples were obtained only from each cow (Fig. 10).

Table 1 Parity, body condition score (BCS), investigation stages and time of feedings of the study groups

\begin{tabular}{|c|c|c|c|c|}
\hline Groups & $\begin{array}{l}\text { Parity } \\
\text { Mean } \pm \text { SE } \\
\text { (minimum-maximum) }\end{array}$ & $\begin{array}{l}\mathrm{BCS} \\
\text { Mean } \pm \mathrm{SE} \\
\text { (minimum-maximum) }\end{array}$ & Investigation stages & Time of feedings \\
\hline Dry cows & $4.2 \pm 0.7(1-6)$ & $3.1 \pm 0.5(2.5-3.5)$ & From 2 to 8 weeks' AP & At 09:30 \\
\hline Close-up & $3.1 \pm 0.8(0-4)$ & $3.7 \pm 0.3(3-4)$ & From 14 to 0 days' AP & At $10: 00$ \\
\hline Fresh-lactation & $3.8 \pm 0.7(1-6)$ & $3.4 \pm 0.6(3-3.75)$ & From 1 to 3 days' PP & At 09:00 \\
\hline Early-lactation & $4.1 \pm 0.4(1-6)$ & $3.1 \pm 0.4(2.5-3.5)$ & From 7 to 30 days' PP & At 09:00 \\
\hline Mid-lactation & $3.7 \pm 0.3(2-5)$ & $2.8 \pm 0.3(2.25-3.25)$ & $\begin{array}{l}\text { From } 31 \text { to } 150 \text { days' PP with milk } \\
\text { production of } \geq 28 \mathrm{Kg} / \text { day }\end{array}$ & At $08: 00$ and $13: 00$ \\
\hline Late-lactation & $4.8 \pm 0.6(2-8)$ & $2.6 \pm 0.5(2-3)$ & $\begin{array}{l}\text { From } 174 \text { to } 375 \text { days' PP with milk } \\
\text { production of }<28 \mathrm{~kg} / \text { day }\end{array}$ & At 07:00 \\
\hline Newborn calves & NA & NA & From 1 to 3 days' PN & At $03: 00$ and $15: 00$ \\
\hline Suckling calves & NA & NA & From 9 to 12 days' PN & At $03: 00$ and $15: 00$ \\
\hline
\end{tabular}

NA Not applicable, AP Antepartum, PP Postpartum, PN Postnatal 


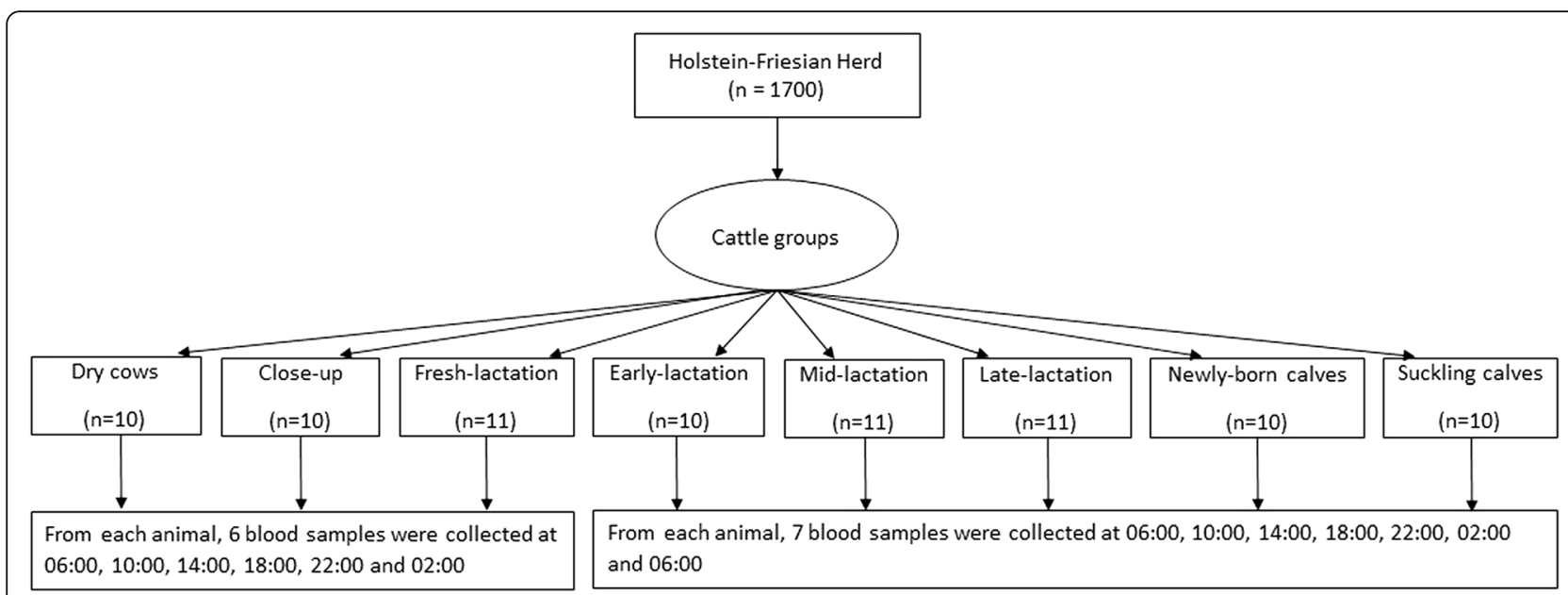

Fig. 10 Schematic diagram representing study design and sampling times

Blood samples were kept at room temperature for about $30 \mathrm{~min}$ to clot. Subsequently, samples were centrifuged at $2000 \times g$ for $20 \mathrm{~min}$ to harvest serum samples (Heraeus Sepatech Labofuge 200, Heraeus Holding $\mathrm{GmbH}$, Hanau, Germany). Serum samples were harvested into $5 \mathrm{ml}$ tubes (Röhrchen, SARSTEDT AG \& Co., Nümbrecht, Germany), using an automatic pipette (Transferpipette 3,5 ml, SARSTEDT AG \& Co., Nümbrecht, Germany), and frozen at $-18^{\circ} \mathrm{C}$ until biochemical assays of albumin, total proteins, glucose, NEFA, BHBA, total bilirubin, cholesterol, urea and creatinine.

\section{Laboratory assays}

The biochemical analyses were carried out in the laboratory of Ruminant Clinic, Free University of Berlin. The serum concentrations of albumin and total proteins were determined using Biuret and Bromocresol green methods, respectively. The measurement of glucose was done using the hexokinase method. A commercial analysis colorimetric method (Randox Laboratories Limited) was used for the quantitative serum determination of NEFA. A quantitative kinetic enzymatic method (Ranbut RB 1007; Randox Laboratories Limited) was used for measurement of BHBA. The determination of total bilirubin was done using a quantitative method (Jendrassik-Gróf). The analysis of cholesterol was performed using a quantitative method (CHOD-PAP). The concentrations of urea and creatinine were measured using enzymatic and kinetic assays, respectively. The sensitivity and coefficient of variation for measurements of 9 studied blood metabolites were provided (Additional file 2). All laboratory assays were carried out automatically using the Roche Cobas Mira Plus CC Chemical Analyzer (Roche Diagnostics, Bern, Switzerland).

\section{Statistical analysis}

Statistical analyses were performed with IBM SPSS Statistics (Version 25, Munich, Germany). The first step is the detection of outlier data for each blood metabolite and values more than 3 standard deviations away from the mean were discarded. No more than $3 \%$ of data were removed from any single measurement. For statistical evaluation, a repeated measures analysis of variance was calculated using the linear mixed procedure, where the animal numbers were the subject, time relative to sampling was set as a repeated variable, and autoregressive [AR(1)] was used as a covariance structure. The model included terms for time relative to sampling, animal groups, and time $\mathrm{x}$ group interaction. The following linear mixed model was used for analysing the effects of sampling time, animal groups and their interactions: $M_{j k}=\mu+T_{j}+G_{k}+T G_{j k}+\varepsilon_{j k}$

Where $M=$ the observed level of serum metabolites, $\mu=$ the overall mean, $T j=$ the fixed effect of sampling time $(j=06: 00,10.00,14: 00,18: 00,22: 00,02: 00,06: 00)$, $G_{k}=$ fixed effect of the cattle groups $(k=1,2,3,4,5,6$, $7,8), \mathrm{TG}_{\mathrm{jk}}=$ Timej and Groupk interaction, $\varepsilon_{\mathrm{jk}}=$ residual error. The main effects were tested using least square differences (LSD). Effects were considered significant at $p<0.05$. In each animal group, the day variations for each metabolite are illustrated as line diagrams (means \pm $\mathrm{SE})$. For comparison among the different animal groups, the mean value of each metabolite was used, and the data are shown as boxplot illustrations.

\section{Supplementary information}

Supplementary information accompanies this paper at https://doi.org/10. 1186/s12917-020-02551-9.

Additional file 1. The amount of milk in $\mathrm{kg}$. (average $=11,500 \mathrm{~kg} / 305 \mathrm{~d}$, $n=1700$ cows). 
Additional file 2. Sensitivity and coefficient of variations for assays of the 9 blood metabolites (clinic laboratory).

\section{Abbreviations}

BHBA: $\beta$-hydroxybutyric acid; NEFA: Non-esterified fatty acids

\section{Acknowledgements}

The authors gratefully acknowledge the manager and staff members of the study farm for their valuable supportive efforts. Without their kind cooperation, this study would have been difficult to conduct.

\section{Authors' contributions}

$\mathrm{HAH}$ designed the study, carried out the study, performed statistical analysis, wrote the original draft, and edited and revised the manuscript. J-PT collected the samples. RS performed the study design and concept, as well as assisted in manuscript review. The authors read and approved the final manuscript.

\section{Funding}

Not applicable.

\section{Availability of data and materials}

The datasets generated and/or analyzed during the current study are available from the corresponding author on reasonable request.

\section{Ethics approval and consent to participate}

All animals were housed and cared according to the German animal welfare act (S. 1206, 13137833-3/18.05.2006). The present study did not involve laboratory animals and only involved blood samples. The blood sampling procedures reported herein were conducted according to Directive 2010/63/ $\mathrm{EU}$, and the regulations of the Institutional Animal Care and Use Committee, Free University of Berlin that follow the OIE standards for use of animals in research purposes. A verbal consent for the use of blood samples before participation in the study was obtained from the herd's owner.

\section{Consent for publication}

Not applicable.

\section{Competing interests}

The authors declare that they have no competing interests.

\section{Author details}

${ }^{1}$ Internal Veterinary Medicine, Department of Animal Medicine, Faculty of Veterinary Medicine, Assiut University, Assiut 71526, Egypt. ${ }^{2}$ Klinik für Klauentiere, Freie Universität Berlin, Königsweg 65, 14263 Berlin, Germany.

Received: 28 February 2020 Accepted: 31 August 2020

Published online: 07 September 2020

\section{References}

1. Macrae Al, Whitaker DA, Burrough E, Dowell A, Kelly JM. Use of metabolic profiles for the assessment of dietary adequacy in UK dairy herds. Vet Rec. 2006:159:655-61.

2. Cellini M, Hussein HA, Elsayed HK, Sayed AS. The association between metabolic profile indices, clinical parameters, and ultrasound measurement of backfat thickness during the periparturient period of dairy cows. Comp Clin Pathol. 2019;28:711-23.

3. Puppel K, Kuczyńska B. Metabolic profiles of cow's blood a review. J Sci Food Agric. 2016:96:4321-8.

4. Wiedemann S, Horstmann K, Piechotta M, Meyer U, Flachowsky G, Kaske M. Intraday variation of metabolic key indicators in serum of dairy cows between week 2 antepartum and week 12 postpartum. Czeh J Anim Sci. 2013;58:343-50

5. Blum JW, Bruckmaier RM, Vacher PY, Münger A, Jans F. Twenty-four- hour patterns of hormones and metabolites in week 9 and 19 of lactation in high-yielding dairy cows fed triglycerides and free fatty acids. J Veterinary Med Ser A. 2000;47:43-60.

6. Plaizier J, Fairfield A, Azevedo P, . Nikkhah A A, Duffield T, Crow G, et al. Effects of Monensin and stage of lactation on variation of blood metabolites within twenty-four hours in dairy cows. J Dairy Sci. 2005:88: 3595-602.
7. Borderas TF, de Passillé AM, Rushen J. Behavior of dairy calves after a low dose of bacterial endotoxin. J Anim Sci. 2008;86:2920-7.

8. Ghaffari MH, MacPherson JA, Berends $H$, Steele M. Diurnal variation of NMR based blood metabolites in calves fed a high plane of milk replacer: a pilot study. BMC Vet Res. 2017;13:271.

9. Oetzel GR. Monitoring and testing dairy herds for metabolic disease. Vet Clin North Am Food Anim Pract. 2004;20:651-74.

10. Hussein HA, Westphal A, Staufenbiel R. Pooled serum sample metabolic profiling as a screening tool in dairy herds with a history of ketosis or milk fever. Comp Clin Pathol. 2013;22:1075-82.

11. Kraft W, Dürr U. Klinische Labordiagnostik in der Tiermedizin. Berlin: Schattauer; 2005.

12. Kaneko JJ, Harvey JW, Bruss ML. Clinical biochemistry of domestic animals San Diego: AcademicISBN 0-12-396305-2; 2008.

13. Tóthová C, Nagy O, Kováč G, Nagyová V. Changes in the concentrations of serum proteins in calves during the first month of life. J Appl Anim Res. 2016:44:338-46.

14. Thomas JS. Overview of plasma proteins and protein electrophoresis. In: Feldman BF, Zinki JG, Jain JC, editors. Schalm's veterinary haematology. 5th ed. New York: Lippincott Williams \& Wilkins; 2000. p. 891-904.

15. Lassen ED. Laboratory evaluation of plasma and serum proteins. In: Thrall MA, editor. Veterinary hematology and clinical chemistry. Philadelphia: Lippincott Williams \& Wilkins; 2004. p. 401-15.

16. Richardson R. Chapter 8 Total proteins. In: Handbook of nonpathologic variations in human blood constituents. Pheladelphia: CRC Press; 1994. p. 12942.

17. Bobbo T, Fiore E, Gianesella M, Morgante M, Gallo L, Ruegg P, et al. Variation in blood serum proteins and association with somatic cell count in dairy cattle from multi-breed herds. Animal. 2017;11(12):2309-19.

18. Piccione G, Messina V, Schembari A, Casella S, Giannetto C, Alberghina D. Pattern of serum protein fractions in dairy cows during different stages of gestation and lactation. J Dairy Res. 2011;78:421-5.

19. Cozzi G, Ravarotto L, Gottardo F, Stefani AL, Contiero B, Moro L, et al. Short communication: reference values for blood parameters in Holstein dairy cows: effects of parity, stage of lactation, and season of production. J Dairy Sci. 2011:94:3895-901.

20. Bittrich S, Philipona C, Hammon HM, Romé V, Guilloteau Blum JW. Preterm as compared with full-term neonatal calves are characterized by morphological and functional immaturity of the small intestine. J Dairy Sci. 2004;87:1786-95.

21. Duffield T, Plaizier JC, Fairfield A, Bagg R, Vessie G, Dick P, et al. Comparison of techniques for measurement of rumen $\mathrm{pH}$ in lactating dairy cows. J Dairy Sci. 2004;87:59-66.

22. Herbein JH, Aiello RJ, Eckler LI, Pearson RE, Akers RM. Glucagon, insulin, growthhormone, and glucose concentrations in blood plasma of lactating dairy cows. J Dairy Sci. 1985;68:320-5.

23. Nielsen $N$, Ingvartsen $K$, Larsen $T$. Diurnal variation and the effect of feed restriction on plasma and Milk metabolites in TMR-fed dairy cows. J Veterinary Med Ser A. 2003:50:88-97.

24. Hammon H, Stümer G, Schneider F, Tuchscherer A, Blum H, Engelhard T, et al. Performance and metabolic and endocrine changes with emphasis on glucose metabolism in high-yielding dairy cows with high and low fat content in liver after calving. J Dairy Sci. 2009:92:1554-66.

25. Staufenbiel R, Rischk U, Schumacher B, Becker W. Beurteilung der insulinund Glucoseregulation bei der Milchkuh mittels Tagesprofilen, dem einfachen und modifizierten Glucosetoleranztest. Dtsch Tierarztl Wochenschr. 1992:99:69-75.

26. Wijayasinghe $M$, Smith N, Baldwin R. Growth, health, and blood glucose concentrations of calves fed high-glucose or high-fat Milk replacers. J Dairy Sci. 1984;67:2949-56.

27. Ospina PA, Nydam DV, Stokol T, Overton TR. Evaluation of nonesterified fatty acids and beta-hydroxybutyrate in transition dairy cattle in the northeastern United States: critical thresholds for prediction of clinical diseases. J Dairy Sci. 2010;93:546-54.

28. DeVries TJ, von Keyserlingk MA, Beauchemin KA. Short communication: diurnal feeding pattern of lactating dairy cows. J Dairy Sci. 2003;86: 4079-82

29. Borrebaek B, Halse K, Tveit B, Dahle HL, Ceh L. Plasma glucose, ketone bodies, insulin, glucagon and enteroglucagon in cows: diurnal variations related to ketone levels before feeding and to the ketogenic effects of feeds. Acta Vet Scand. 1990;31:5-15. 
30. Grummer RR. Nutritional and management strategies for the prevention of fatty liver in dairy cattle. Vet J. 2008;176:10-20.

31. Beauchemin KA, Maekawa M, Christensen DA. Effect of diet and parity on meal patterns of lactating dairy cows. Can J Anim Sci. 2002;82:215-23.

32. Alhojaily SR, Stott R, Rutigliano H, Stevens J. Effects of lactation and negative energy balance on endometrial expression of selected transcripts of Holstein dairy cows at day 7 post-ovulation. J Anim Sci. 2018;96:177.

33. Diao $\mathrm{Q}$, Zhang $\mathrm{R}$, Tong $\mathrm{FT}$. Review of strategies to promote rumen development in calves. Animals. 2019;9:490.

34. Casale G. Circadian rhythms and aging. Minerva Med. 1983;74:1233-40.

35. Kessler E, Gross J, Bruckmaier R, Albrecht C. Cholesterol metabolism, transport, and hepatic regulation in dairy cows during transition and early lactation. J Dairy Sci. 2014;97:5481-90.

36. Egli CP, Blum JW. Clinical, hematological, metabolic and endocrine traits during the first three months of life of suckling simmentaler calves held in a cow-calf operation. J Veterinary Med Ser A. 1998;45:99-118.

37. Mohri M, Sharifi K, Eidi S. Hematology and serum biochemistry of Holstein dairy calves: age related changes and comparison with blood composition in adults. Res Vet Sci. 2007;83:30-9.

38. Gustafsson AH, Palmquist DL. Diurnal variation of rumen ammonia, serum urea, and milk urea in dairy cows at high and low yields. J Dairy Sci. 1993; 76:475-84.

39. Milletich S. Circadiane Rhythmen hämatologischer und chemischer Blutparameter beim HengstDissertation Veterinary Medicine. Wien: Universität Wien; 2002.

40. Jasarevic M. Chronobiologische hämatologische Untersuchungen beim SchafDissertation Veterinary Medicine, Universität Wien; 1996.

41. Whittet K, Watson A, Erickson G, Klopfenstein T. Factors affecting urinary creatinine in heifers and cows. Translation Anim Sci. 2019;3:532-40.

42. Tierschutzgesetz. Bundesrepublik Deutschland BI. I S. 1206, 13137833-3 18. 05. 2006.

\section{Publisher's Note}

Springer Nature remains neutral with regard to jurisdictional claims in published maps and institutional affiliations.

Ready to submit your research? Choose BMC and benefit from:

- fast, convenient online submission

- thorough peer review by experienced researchers in your field

- rapid publication on acceptance

- support for research data, including large and complex data types

- gold Open Access which fosters wider collaboration and increased citations

- maximum visibility for your research: over $100 \mathrm{M}$ website views per year

At $\mathrm{BMC}$, research is always in progress.

Learn more biomedcentral.com/submissions 